\title{
Hubungan antara Gangguan Tidur dengan Gangguan Mental Emosional Anak Usia 4-6 Tahun di Semarang
}

Adriana Lukmasari, Fitri Hartanto, Tjipta Bahtera, Muhammad Heru Muryawan

Departemen Ilmu Kesehatan Anak Fakultas Kedokteran Universitas Diponegoro/RSUP Dr. Kariadi, Semarang

Latar belakang. Tidur adalah salah satu kebutuhan dasar untuk mendukung tumbuh kembang anak. Diagnosis dini gangguan tidur masih asing bagi orang tua karena pengetahuan tentang kualitas tidur yang kurang. Gangguan tidur dikaitkan dengan regulasi emosional otak.

Tujuan. Menentukan hubungan antara gangguan tidur dan mental emosional pada anak usia 4-6 tahun di Semarang.

Metode. Penelitian cross sectional pada anak usia 4-6 tahun sekolah taman kanak-kanak di Kota Semarang dari bulan April-Mei 2016 berdasarkan kriteria inklusi. Cluster sampling dilakukan dalam seleksi mata pelajaran. Gangguan skala tidur untuk anak sleep disturbances scale for children (SDSC) digunakan sebagai alat skrining, sementara perkembangan emosi dan tingkah laku anak digunakan SDQ. Data dianalisis dengan menggunakan SPSS 22, chi-square, dan Fisher exact dengan signifikansi $\mathrm{p}<0,05$.

Hasil. Didapat 208 subyek dengan prevalensi gangguan tidur 73,6\%. Terdapat hubungan yang signifikan dari gangguan tidur dengan jumlah SDQ skor (RP 2,3, IK95\%: 1,1-4,7; p=0,02), skor emosional (RP 2,7, IK95\%: 1,3-5,5; p=0,003) dan melakukan skor (RP 1,8, IK95\%: 1,1-2,8; $\mathrm{p}=0,005)$. Tidak terdapat hubungan yang signifikan dari gangguan tidur pada hiperaktif, masalah dengan teman sebaya, dan perilaku prososial. Kategori pendapatan orang tua, tingkat pendidikan ibu, dan jenis kelamin tidak terbukti sebagai faktor perancu.

Kesimpulan. Terdapat hubungan antara gangguan tidur dan masalah mental emosional dalam 4-6 tahun anak. Sari Pediatri 2017;18(5):345-9

Kata kunci: gangguan tidur, masalah mental emosional

\section{Association between Sleep Disturbance and Mental Emotional Problem in 4-6 Years Old Children in Semarang}

Adriana Lukmasari, Fitri Hartanto, Tjipta Bahtera, Muhammad Heru Muryawan

Background. Sleep is one of children's basic need to support growth and development. Early diagnosis of sleep disturbance is still unfamiliar due to the lack of parents knowledge about sleep quality. Sleep disturbance is associated with brain's emotional regulation Objective. To determine the association between sleep disturbance and mental emotional problem in 4-6 years old children in Semarang Methods. This was a cross sectional study in 4-6 years old children who match inclusions criteria in acredited A and B Kinder Garten school in Semarang from April-May 2016. Cluster sampling was performed in subjects selection. Sleep Disturbance scale for children (SDSC) was used as a screening tools of sleep distubance while the strength and difficulties questionnaire (SDQ) for mental emotional problem. Data was analyzed using SPSS 22, chi-square and Fisher.s Exact test with significancy p $<0,05$

Results. There were 208 subjects. The prevalence of sleep disturbance was 73,6\%. There was significant association of sleep disturbance with total SDQ score (RP 2,3,95\%CI: 1,1-4,7; p=0,02), emotional score (RP 2,7,95\%CI: 1,3-5,5; p=0,003) and conduct score (RP 1,8, 95\%CI: 1,1-2,8; $\mathrm{p}=0,005)$. There were no significant association of sleep disturbance on hyperactivity, peer problem score and prosocial behaviour. Parents income category, mother educational level and gender were not proven as confounding factors.

Conclusion. There was association between sleep disturbance and mental emotional problem in 4-6 years old children. Sari Pediatri 2017; 18(5):345-9

Keywords: sleep disturbance, mental emotional problem

Alamat korespondensi: Dr. Adriana Lukmasari. Departemen Ilmu Kesehatan Anak Fakultas Kedokteran Universitas Diponegoro/ RSUP Dr. Kariadi Semarang Jl. Dr. Soetomo 16, Semarang. Email : adrianalukma@gmail.com 
Adriana Lukmasari dkk: Hubungan antara gangguan tidur dengan gangguan mental emosional anak usia 4-6 tahun

T idur merupakan suatu keadaan berkurangnya tanggapan dan interaksi dengan lingkungan yang bersifat reversibel dan berlangsung cepat. ${ }^{1}$ Jumlah dan lama tidur bervariasi menurut usia bayi dan anak. Semakin besar anak maka kebutuhan tidur semakin berkurang. Tidur terdiri atas dua komponen, yaitu rapid eye movement (REM) dan non rapid eye movement (non-REM) yang terjadi secara bergantian yang membentuk suatu siklus tidur. ${ }^{2}$ Tidur memiliki beberapa fungsi, di antaranya, menyimpan energi, adaptasi, dan konsolidasi memori. Penelitian juga menyebutkan bahwa tidur bermanfaat dalam regulasi emosi. ${ }^{3}$ Tidur fase REM menunjukkan proses yang sangat penting dimana pada fase itu terjadi pelepasan neurotransmitter, seperti noradrenergik ke daerah korteks medial prefrontal otak dan amigdala. Adanya gangguan tidur pada anak akan memengaruhi keseimbangan neurotransmitter di daerah pusat emosi (amigdala). Gangguan tidur berhubungan dengan status emosi dan tingkah laku pada anak dan remaja. ${ }^{4}$

Lima tahun pertama kehidupan seorang anak merupakan masa kritis perkembangan emosi karena pada masa ini terbentuknya dasar-dasar kepribadian manusia, kemampuan berpikir, ketrampilan berbahasa, berbicara dan bertingkah laku sosial. ${ }^{5}$ Perkembangan emosi dan tingkah laku anak dapat dinilai dengan the strengths and difficulties questionnaire (SDQ). ${ }^{6}$

Gangguan tidur pada anak jarang didiagnosis secara dini karena pemahaman orang tua yang kurang mengenai kebutuhan tidur seorang anak. Penelitian di Beijing menyebutkan prevalensi gangguan tidur pada anak usia 2-6 tahun 23,5\%.7 Penelitian yang dilakukan di lima kota besar di Indonesia, didapatkan prevalensi gangguan tidur pada anak usia di bawah 3 tahun $44,2 \%$ dari 385 sampel penelitian. ${ }^{8}$ Penelitian tersebut juga mengobservasi faktor yang berhubungan dengan durasi gangguan tidur, ditemukan hubungan bermakna antara jumlah waktu tidur siang dan waktu mulai tidur malam dengan gangguan tidur. Namun, faktor sosiodemografi seperti tingkat pendidikan, pekerjaan orang tua, dan lain-lain tidak memiliki hubungan yang bermakna dengan gangguan tidur. ${ }^{8}$ Penelitian ini dilakukan untuk mengetahui hubungan gangguan tidur dengan mental emosional anak.

\section{Metode}

Penelitian dilakukan di taman kanak-kanak wilayah kota Semarang pada anak usia 4-6 tahun, mulai bulan April 2016 sampai dengan jumlah sampel terpenuhi. Penelitian observasional analitik dengan rancangan cross sectional. Besar sampel minimal adalah 106 anak dan dipilih secara cluster sampling. Gangguan tidur diukur dengan sleep disturbances scale for children (SDSC). Metode SDSC digunakan karena prinsip analisis komponen yang kuat, normalitas yang distandardisasi, dan usia yang dipakai sesuai dengan yang diteliti. Kuesioner SDSC terdiri atas 26 pertanyaan, dinilai dalam 5 poin skala intensitas atau frekuensi. ${ }^{9}$ Orang tua diminta untuk mengingat pola tidur anak mereka pada waktu keadaan sehat selama enam bulan terakhir. Penilaian SDSC ini dilakukan dengan menggunakan rentang angka mulai dari 1 sampai dengan 5. Angka 1 untuk tidak pernah, 2 untuk jarang ( 1 atau 2 kali per bulan atau kurang), 3 untuk kadang-kadang (1 atau 2 kali seminggu), 4 untuk sering (3 sampai 5 kali seminggu), dan 5 untuk selalu (setiap hari). Setelah itu, akan diperoleh nilai total dengan cara dijumlahkan dan didapatkan penilaian akan adanya gangguan tidur pada anak. Skor gangguan tidur memiliki rentang dari 26 hingga 130. Total skor di atas 39 diklasifikasikan sebagai gangguan tidur, sedangkan skor di bawah atau sama dengan 39 diklasifikasikan normal. ${ }^{9}$ Perkembangan mental emosional anak, berupa gejala emosional, masalah perilaku, hiperaktivitas, masalah hubungan antar sesama dan perilaku prososial diukur dengan the strength and difficulties questionnaire (SDQ). Kuesioner terdiri atas 25 poin dengan 3 interpretasi, yaitu normal, borderline dan abnormal. Skor borderline dimasukkan ke dalam abnormal. Uji hipotesis dilakukan dengan uji non parametrik menggunakan uji chi-square dan Fisher exact test. Batas kemaknaan adalah $\mathrm{p} \leq 0,05$ dengan interval kepercayaan 95\%. Analisis data dilakukan dengan program SPSS for windows versi 22.0 (SPSS Inc, USA).

Sebelum penelitian dilakukan, prosedur penelitian telah dimintakan ethical clearance dari Komisi Etik Penelitian Kesehatan/ Kedokteran FK UNDIP/ RSUP Dr. Kariadi Semarang. Setiap subjek penelitian akan dimintakan persetujuan orang tua/ wali dengan menggunakan informed consent tertulis.

\section{Hasil}

Secara keseluruhan, rerata umur subyek adalah $5,4 \pm 0,66$ tahun dengan usia termuda adalah 4 tahun 
dan tertua adalah 6 tahun. Jenis kelamin subyek penelitian sebagian besar adalah perempuan $(54,8 \%)$.

Hasil uji statistik menunjukkan hubungan tidak bermakna antara status gizi anak $(\mathrm{p}=0,7)$, tingkat pendidikan ibu $(\mathrm{p}=0,3)$ dan penghasilan ibu $(\mathrm{p}=0,7)$ dengan kejadian gangguan tidur. Begitu pula didapatkan hubungan tidak bermakna antara status gizi anak $(\mathrm{p}=0,2)$, tingkat pendidikan ibu $(\mathrm{p}=0,3)$ dan penghasilan ibu $(\mathrm{p}=0,8)$ dengan kejadian gangguan mental emosional.

Didapatkan hubungan yang bermakna antara skor SDSC dengan skor SDQ total $(\mathrm{p}=0,02 ; \mathrm{RP}=2,3)$, skor emosi $(\mathrm{p}=0,003 ; \mathrm{RP}=2,7)$ dan skor perilaku $(\mathrm{p}=0,005$; $\mathrm{RP}=1,8)$ (Tabel 2). Sementara tidak didapatkan hubungan yang bermakna antara skor SDSC dengan skor hiperaktivitas $(\mathrm{p}=0,4 ; \mathrm{RP}=1,4)$, skor pertemanan antar sesama $(\mathrm{p}=0,4 ; \mathrm{RP}=1,4)$, dan skor perilaku prososial $(\mathrm{p}=0,2 ; \mathrm{RP}=4,3)$.

\section{Pembahasan}

Subyek penelitian terbanyak adalah perempuan $(54,8 \%)$. Jenis kelamin tersebut tidak menunjukkan hubungan yang bermakna dengan kejadian gangguan tidur pada anak. ${ }^{10} \mathrm{Hal}$ tersebut sesuai dengan penelitian sebelumnya bahwa tidak ada perbedaan jenis kelamin terhadap risiko terjadinya gangguan tidur. Pada penelitian ini didapatkan prevalensi gangguan tidur pada anak usia 4-6 tahun 73,6\%. Hasil tersebut sesuai dengan sebuah penelitian di Cina yang melaporkan bahwa prevalensi gangguan tidur pada anak usia 3-6 tahun $78,8 \% .^{11}$

Tingkat pendidikan dan penghasilan ibu atau orang tua bukan sebagai penyebab gangguan tidur pada anak. Berdasarkan penelitian di Cina ${ }^{12}$ disebutkan bahwa faktor risiko sosiodemografis yang berpengaruh secara bermakna terhadap gangguan tidur pada anak

Tabel 1. Karakteristik subyek penelitian $(\mathrm{n}=208)$

\begin{tabular}{lcc}
\hline Karakteristik & $\begin{array}{c}\text { Rerata } \pm \text { SB; median } \\
(\text { min-maks })\end{array}$ & $\mathrm{n}(\%)$ \\
\hline Usia (tahun) & $5,4 \pm 0,66 ; 5(4-6)$ & - \\
Jenis kelamin & - & $94(45,2)$ \\
$\quad$ Laki-laki & - & $114(54,8)$ \\
Perempuan & & - \\
Usia berdasarkan jenis kelamin & $5,4 \pm 0,65 ; 6(4-6)$ & - \\
Laki-laki & $5,3 \pm 0,67 ; 5(4-6)$ & \\
Perempuan & $18,3 \pm 4,20 ; 17,5(10-40)$ & $3(1,4)$ \\
Berat badan & & $14(6,7)$ \\
Kategori berat badan & - & $178(85,6)$ \\
Sangat rendah & - & $7(3,4)$ \\
Rendah & - & $6(2,9)$ \\
Normal & - & - \\
Berlebih & - & \\
Sangat berlebih & & \\
\hline
\end{tabular}

Tabel 2. Hubungan SDSC dengan SDQ

\begin{tabular}{lcc}
\hline Kategori Skor & $\begin{array}{c}\text { Rasio prevalensi } \\
(95 \% \mathrm{IK})\end{array}$ & $\mathrm{p}^{*}$ \\
\hline Skor SDSC dengan skor SDQ total & $2,3(1,1 \mathrm{~s} / \mathrm{d} 4,7)$ & 0,02 \\
Skor SDSC dengan skor emosi & $2,7(1,3 \mathrm{~s} / \mathrm{d} 5,5)$ & 0,003 \\
Skor SDSC dengan skor perilaku & $1,8(1,1 \mathrm{~s} / \mathrm{d} 2,8)$ & 0,005 \\
Skor SDSC dengan skor hiperaktivitas & $1,4(0,6 \mathrm{~s} / \mathrm{d} 3,0)$ & 0,4 \\
Skor SDSC dengan skor pertemanan antar sesama & $1,4(0,7 \mathrm{~s} / \mathrm{d} 2,6)$ & 0,4 \\
Skor SDSC dengan skor perilaku prososial & $4,3(0,6 \mathrm{~s} / \mathrm{d} 32,4)$ & 0,2 \\
\hline *Uji $\chi^{2}$; SDSC: sleep disturbance scale for children; SDQ: the strength and difficulties questionnaire
\end{tabular}


adalah paparan elektronik, seperti televisi, komputer atau internet, jam tidur orang tua yang pendek dan tidak diterapkannya sleep hygine yang baik pada anak. Pengamatan kami selama melakukan penelitian, hampir semua orang tua tidak menerapkan sleep hygiene kepada anak dengan tidak memandang tingkat pendidikan maupun tingkat penghasilan orang tua. Sleep hygine meliputi penerapan jam tidur anak, penggunaan lampu teduh ketika tidur malam, menjaga kebersihan tempat tidur dan tidak menempatkan barang elektronik di dalam kamar. Selain itu, jumlah menonton televisi, bermain video games dan bermain handphone tidak pernah dilakukan pembatasan. Kondisi ruang tidur dengan televisi sehingga sebelum anak tertidur mendapat paparan televisi juga tidak pernah disadari oleh orang tua sebagai penyebab gangguan tidur. Bahkan, kadang anak dan orang tua tertidur dalam kondisi televisi masih menyala. Televisi, handphone atau komputer memiliki cahaya dengan intensitas cukup besar. Paparan sinar tersebut dikatakan pada beberapa penelitian menganggu sekresi hormon melatonin. Pada kondisi terpapar elektronik, sekresi hormon melatonin terganggu sehingga mengganggu siklus tidur. Hal tersebut mungkin menjadi salah satu penyebab prevalensi gangguan tidur yang tinggi di penelitian ini.

Analisis terhadap gangguan tidur dengan perkembangan mental emosional anak dilakukan dengan chi square. Didapatkan hubungan antara gangguan tidur dengan mental emosional anak. Gangguan tidur memiliki rasio prevalens 2,7 kali lipat untuk terjadi gangguan mental emosional pada anak usia 4-6 tahun. Marcello $^{13}$ melaporkan bahwa sekresi hormon kortisol didapatkan lebih tinggi pada anak yang mengalami gangguan tidur. Kadar hormon yang tinggi tersebut akan menyebabkan anak lebih bersifat emosinal dan temperamental. Gangguan tidur yang terjadi pada anak akan menurunkan sekresi dari hormon pertumbuhan sehingga insulin growth factor-1 (IGF-1) menurun. Insulin growth factor-1 merupakan asam mino yang memacu faktor pertumbuhan yang juga memengaruhi pertumbuhan sistem saraf. Proses neurogenesis dari hipokampus merupakan hal penting untuk terjadinya kematangan fungsi kognitif dan tingkah laku. Gangguan tidur dapat mengganggu respon amigdala yang ada di otak. Amigdala merupakan bagian otak yang berfungsi sebagai pusat pengaturan emosi dan tingkah laku. Pada gangguan tidur akan terjadi hiperreaktivitas dari amigdala yang pada sebuah penelitian digambarkan dalam fungsional magnetic resonance imaging (FMRI). ${ }^{14}$ Penelitian lain juga membuktikan bahwa pada anak dengan penurunan jumlah tidur mengalami gangguan pada hubungan antara amigdala dengan korteks pre frontal. Korteks pre frontal dalam hal ini berfungsi sebagai pengatur atau inhibisi terhadap hiperreaktivitas dari amigdala. Gangguan tidur menghambat proses inhibisi tersebut sehingga tidak terjadi kontrol balik terhadap amigdala.

Gangguan tidur memiliki rasio prevalens 2,7 kali lipat untuk menjadi gangguan emosi dan 1,8 kali lipat untuk menjadi gangguan perilaku. Hasil tersebut sesuai dengan penelitian korelasi yang dilakukan oleh Zhijun ${ }^{11}$ yang melaporkan bahwa terdapat hubungan yang kuat antara gangguan tidur dengan gangguan emosi, perilaku, dan hiperaktivitas. Sementara itu, pada gangguan hubungan antar sesama dan perilaku prososial tidak didapatkan korelasi. Penelitian GuangHai ${ }^{15}$ juga melaporkan bahwa terdapat hubungan antara gangguan tidur dengan emosi, tingkah laku, dan hiperaktivitas.

Tidak didapatkan hubungan antara gangguan tidur dengan hiperaktivitas. Dalam sebuah penelitian lain oleh Kobrat ${ }^{16}$ melaporkan kondisi anak dengan hiperaktif atau attention defisit hyperactivity disorder (ADHD) lebih banyak terjadi gangguan tidur dibandingkan anak normal. Kondisi defisiensi dopamin, seperti yang terjadi pada anak hiperaktif maupun ADHD, menyebabkan sekresi melatonin juga menurun sehingga terjadi gangguan tidur. ${ }^{17}$ Hasil analisis gangguan tidur dengan perilaku prososial tidak menunjukkan hubungan. Perilaku prososial merupakan faktor protektif pada penilaian gangguan mental emosi anak.

Dua kuesioner yang telah divalidasi di Indonesia menjadi kekuatan penelitian ini. Selain itu, jumlah sampel yang cukup banyak di luar sampel minimal yang ada dengan mengambil secara acak 16 murid taman kanak-kanak di kota Semarang. Penelitian dilakukan dalam satu waktu sehingga tidak didapatkan drop out.

Keterbatasan peneltian ini adalah pertama, belum digunakannya polisomnografi sebagai gold standart diagnosis gangguan tidur pada anak. Kedua, penggunaan kuesioner yang dilaporkan atau diisi orang tua juga masih memungkinkan terjadinya recall bias. Ketiga, pemeriksaan fisik secara keseluruhan pada anak yang menjadi sampel hendaknya juga dilakukan, tetapi tidak dilakukan. Disimpulkan terdapat hubungan antara gangguan tidur dengan 
gangguan mental emosional anak. Perlu dilakukan penelitian lebih lanjut dengan pemantauan yang lebih lama atau dengan desain prospektif sehingga dapat menjelaskan hubungan sebab akibat lebih jelas dan dilakukan pelatihan kepada guru atau tenaga pengajar untuk dapat melakukan skrining gangguan tidur dan gangguan mental emosional anak. Apabila didapatkan masalah tersebut diharapkan dapat memberikan arahan untuk tata laksana lebih lanjut di Dokter Spesialis Anak atau klinik tumbuh kembang.

\section{Daftar pustaka}

1. Tikotzky L DMG, Har-Toov J, Dollberg S, Bar-Haim Y, Sadeh A. Sleep and physical growth in infants during the first 6 months. J Sleep Res 2010;9:103-10.

2. Chokroverty S. Overview of sleep and sleep disorders. Indian J Med Res 2010;131:126-40.

3. Jonathan RL, Schwartz TR. Neurophysiology of sleep and wakefulness: basic science and clinical implications. Curr Neuropharmacol 2008;6:367-78.

4. Gregory AM, Sadeh A. Sleep, emotional and behavioral difficulties in children and adolescents. Sleep Med Rev 2012;16:129-36.

5. Saarni C. Emotional development in childhood. Encyclopedia on early childhood development. Sonoma State University; 2011.

6. Ahmad GM, Ahad IM, Abdollahi G. Scale validation of the strengths and difficulties questionnaire in Iranian children. Iran J Psychiatry 2007;2:65-71.

7. Oerkermann F, Pluck MS, Schredl M, Heinz K, Mitschke A, Wiater A, dkk. Prevalence and course of sleep problems in childhood. Sleep 2007;30:1371-7.

8. Sekartini R, Adi NP. Gangguan tidur pada anak usia bawah tiga tahun di lima kota di Indonesia. Sari Pediatri 2006;7:188-93.

9. Natalita C, Sekartini R, Pusponegoro H. Skala gangguan tidur untuk anak (SDSC) sebagai instrumen skrining gangguan tidur pada anak sekolah lanjutan tingkat pertama. Sari Pediatri 2011;12:365-72.

10. Liu X, Liu L, Owen JA, Kaplan DL. Sleep patterns and sleep problem among schoolchildren in the United States and China. Pediatrics 2005;115:241-9.

11. Zhijun L, Wang G, Geng L. Sleep patterns, sleep disturbances and associated factors among chinese urban kindergarten children Behav Sleep Med 2016;14:100-17.

12. Liu S, Zhu S, Jin X, Yan C, Wu S, Jiang F, Shen X. Risk factors associated with short sleep duration among Chinese schoolaged children. Sleep Med 2010;11: 907-16.

13. Clow A, Hucklebridge F, Stalder T, Evans P, Thorn L. The cortisol awakening response: more than a measure of HPA axis function. Neuroscience and Biobehavioral Rev 2009:1-7.

14. Gruber R, Cassoff J, Frenette S, Wiebe $S$ and Carrier J. Impact of sleep extension and restriction on children's emotional lability and impulsivity. Pediatrics 2012; 130: 1155-61.

15. GuangHai W, GuangXing X, Zhijun L, Ning L, Rui M, Entao Z. Sleep patterns and sleep disturbance among chinese school-aged children: prevalence and associated factors. Sleep Med 2013;14:45-52.

16. Kobrat C, Nattapong J, Chandita, Weerasak C. Increase sleep disturbances in thai children with attention deficit hyperactivity disorder compared with typically developing children. Behav Sleep Med 2016:1-10.

17. Owens JA. A clinical overview of sleep and attention-deficit/ hyperactivity disorder in children and adolescents. J Can Acad Child Adolesc Psychiatry 2009;18:1-11. 